\title{
Inter-decadal Spatiotemporal Variations of Aridity Based on Temperature and Precipitation in Inner Mongolia, China
}

\author{
Siqin Tong, ${ }^{1,2}$, Jiquan Zhang ${ }^{1 *}$, Yuhai Bao ${ }^{2}$ \\ ${ }^{1}$ School of the Environment, Natural Disaster Research Institute, Northeast Normal University, \\ Changchun 130024, People's Republic of China \\ ${ }^{2}$ College of Geographical Science, Inner Mongolia Normal University, \\ Hohhot 010022, People's Republic of China
}

Received: 27 July 2016

Accepted: 15 October 2016

\begin{abstract}
In the past few decades, drought has been a frequent phenomenon in many parts of the world, especially in arid and semi-arid regions. Hence in order to better predict the development trend of drought in Inner Mongolia and formulate corresponding countermeasures for disaster prevention and mitigation, for this paper we calculated the aridity index according to the annual mean precipitation and temperature data of 109 stations covering 1961-2010. The study result indicated that the mean aridity degree was increasing from west to east and was mainly characterized by moderate aridity; from 1961 to 2010 the change of aridity has been decreasing while aridity has been increasing, especially after the abrupt changing point in 1995 . Moreover, the decreasing area of aridity took up $82.6 \%$ while the increasing area only occupied $17.4 \%$ of the whole area. During a 50-year time scale, the annual mean aridity oscillation periodicity was at 49a, 25a, and7a, and Inner Mongolia was still at a stage of aridity that might last for a long time. Regarding different decades, the climate of Inner Mongolia was relatively humid in the 1980s; however, as time went by the area of moderate aridity degree increased while the humidity area decreased in the early $21^{\text {st }}$ century. Therefore, it was clear that the climate was becoming drier year after year. From 1960 to 2010, contours lower than 30 shifted toward longitude direction and contours more than 30 moved in the direction of latitude.
\end{abstract}

Keywords: climatic aridity index, spatiotemporal variation, aridificaiton, Inner Mongolia

\section{Introduction}

The fourth assessment report of the IPCC announced that surface temperature has increased about $0.74^{\circ} \mathrm{C}$ over hundreds of years [1]. There is no denying that global

*e-mail: zhangjq022@nenu.edu.cn warming is an undeniable truth [2]. Global warming has had considerable impact on several aspects, such as water cycling of the globe and region, dry-wet climate, and spatial variation map. Dry-wet shifted in general and presented the characteristics of different fluctuations between west-east and north-south [3]. Aridity has been continuously increasing for 25 years and the humidity area has been shrinking and this phenomenon has been severe in the past 10 years [4]. However, the variation situation 
of arid climate and humid climate in different geography regions are different. From the 1960s, the humidity degree of Ningxia (China) was growing more arid than in past years [5]. The annual aridity index of Xinjiang (China) was getting lower and lower [6]. The trend of aridity in Xilin Gol was rising on the whole from 1981 to 2007 [7]. From the previous studies above, it could be concluded that under the background of global warming, different regions and different ecological systems demonstrated different climatic characteristics and trends of aridity and humidity. Therefore, the study on dry wet climate has revealed great practical implications and meanings to specific or certain climate variations.

The Inner Mongolia Autonomous Region is located in the northern part of the People's Republic of China. It is the third largest subdivision of China. The grassland of Inner Mongolia occupies 22\% of its total area, which is not only the nations' most important grazing base but also a significant ecological barrier. Agriculture, grazing, and exploitation of mineral resources are given priority in its dominant economic foundation, and Inner Mongolia is also a major mining district, possessing large reserves of coal, iron, and rare earth minerals, which has made it a major industrial region today. However, industry development had taken a lot of ecological water and continuous aridity has led to the grassland desertification and ecological deterioration day by day. Since 2000 , the relatively lower amounts of precipitation in most parts of Inner Mongolia and the relatively high temperature as well as the different degrees of drought have contributed to the reduction of crop yields in the drought-stricken area. In 2010, due to the development of upstream mining industry and associated industries, the wetlands of Wulagai of Xilin Gol league (China) has been driven to a dry state with nearly $50,000 \mathrm{~km}^{2}$ of Ujimqin grassland becoming desertified step by step. Although a great number of active measures have been taken by state and regional governments to protect and restore ecological grassland in recent years, the use of water resource is still a dilemma as a result of economic development - particularly the rapid development of the mining industry.

The study is under the background of the entire region's aridity situation and aims to relieve the tension of water supply of Inner Mongolia and given references for how to save water resources. The aridity index is viewed as one of the most important indicators of a climate's overall situation. It can reflect the whole regional climate change from two meteorological elements with a combination of temperature and precipitation. At present, the aridity index has already become an important climate index of global warming, and it has been widely applied to study climate division, climate change, and aridity trends, particularly in the mid-latitude arid and semi-arid regions as well as desertification [8]. The study was based on geographical information and other climatology algorithms and made use of De Martonne in order to get the ratio of aridity index through precipitation and temperature. The study analyzed the spatio-temporal variations of annual temperature and annual precipitation according to the statistics of 109 meteorological observation stations under the background of global warming from 1961 to 2010 in Inner Mongolia. The study hopes to reveal the general characteristics and regularity of climate change. Finally, the study will provide Inner Mongolia with some technological support and give some references for disaster prevention and mitigation work to a related department.

\section{Material and Methods}

\section{Study Area}

The Inner Mongolia Autonomous Region is situated in northern China at $37^{\circ} 24^{\prime}-53^{\circ} 23^{\prime}$ north latitude and $97^{\circ} 12^{\prime}$ $126^{\circ} 04^{\prime}$ east longitude (Fig. 1), with an area of 1.183 million $\mathrm{km}^{2}$. The geography is vast and topography and the average sea level is above 1,000-2,000 m, so most of Inner Mongolia is a plateau in altitude and its topography is plains, mountains, and high plain mosaic distribution. Due to its elongated shape, Inner Mongolia has a wide variety of regional climates. Throughout the region, the climate is basically monsoon climate and the annual average temperature is $4-9^{\circ} \mathrm{C}$. The summer is very hot and relatively humid except in the west, where it remains dry at $19-26^{\circ} \mathrm{C}$, while the winter of Inner Mongolia is very long, cold, and dry at $-30 \sim-11^{\circ} \mathrm{C}$. The range of annual precipitation is from $50 \mathrm{~mm}$ in arid regions to $500 \mathrm{~mm}$ in humid regions. Weather type belongs to the typical continental monsoon climate of dry and rainless (except for the humid area of the great Hinggan Mountains). Most of Inner Mongolia is located in an arid and semi-arid climate zone. Although the grassland is large, grassland desertification is serious and the ecological environment is fragile.

\section{Data}

The database consists of air temperature and precipitation records at 109 stations in Inner Mongolia from 1961 to 2010. The annual average temperature and annual precipitation were computed. The geographical coordinates were built for the meteorological observation station in order to establish standard distribution sites of latitude and longitude with the aid of GIS.

\section{Methods}

\section{De Martonne Index}

Aridity index (Idm), which particularly means the climate dryness in this paper, is an indicator of the wet and dry in a region, and is generally presented by the ration of water balance and heat balance. Since 1990, many scholars have put forward about 32 kinds of methods and models to calculate the dryness/wetting index [9]. The principles of those methods are different from each other and have their own advantages and disadvantages. Among them, the simplest method is to calculate the temperature 


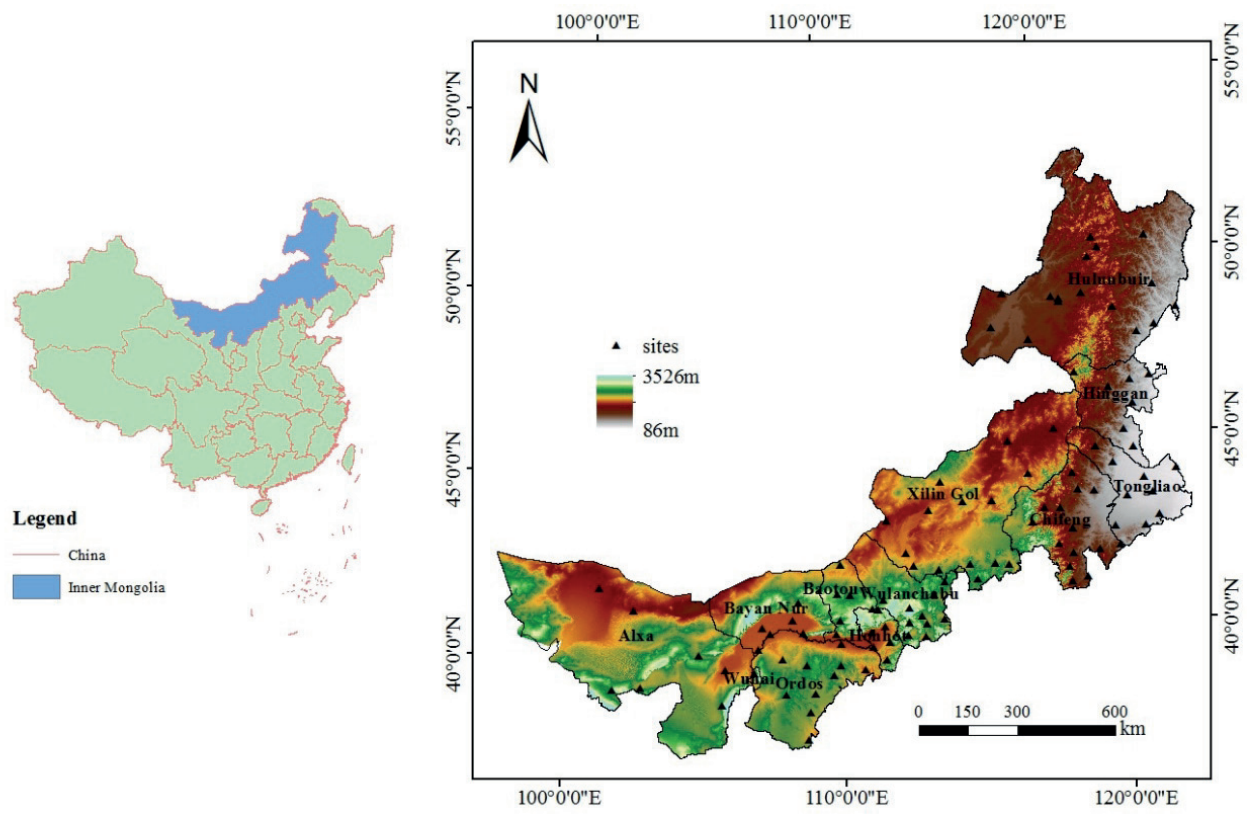

Fig. 1. Map of geographical location of Inner Mongolia and the distribution of weather stations.

and precipitation to get aridity. In 1926, French scholar Emmanuel de Martonne proposed a simple calculation method of aridity index, which has a certain relationship with vegetation and soil distribution, and the algorithm is described as Formula 1:

$$
\mathrm{I}_{\mathrm{dm}}=\frac{\mathrm{P}}{\mathrm{T}+10}
$$

...where Idm is the de Martonne aridity index, $\mathrm{P}$ is annual precipitation $(\mathrm{mm})$, and $\mathrm{T}$ is annual mean air temperature. As precipitation is the numerator, the greater the aridity index, the wetter it is; the smaller the aridity index, the drier it is. Typically, Idm less than 10 indicates severe dryness, Idm more than 10 and less than 30 indicates moderate dryness, and Idm greater than 30 indicates wetness.

\section{Trend Analysis}

The linear regression method can simulate the annual change trend of aridity in each pixel and the algorithm is shown as follows (Formula 2):

$$
\theta_{\text {slope }}=\frac{\mathrm{n} \times \sum_{\mathrm{i}=1}^{\mathrm{n}} \mathrm{i} \times \mathrm{C}_{\mathrm{i}}-\sum_{\mathrm{i}=1}^{\mathrm{n}} \mathrm{i} \sum_{\mathrm{i}=1}^{\mathrm{n}} \mathrm{C}_{\mathrm{i}}}{\mathrm{n} \times \sum_{\mathrm{i}=1}^{\mathrm{n}} \mathrm{i}^{2}-\left(\sum_{\mathrm{i}=1}^{\mathrm{n}} \mathrm{i}\right)^{2}}
$$

...where $\theta_{\text {slope }}$ is the trend slope aridity index, $\mathrm{n}$ is the study period (1961 to 2010 in this paper), and $C_{i}$ is the annual mean aridity in the ith year. When $\theta_{\text {slope }}<0$ it means a drying trend and vice versa. Using the $F$ test to determine whether the change is significant or not, and the significant test can only represent the confidence level of changes and has nothing to do with the speed of changes. The F test was calculated as follows:

$$
\mathrm{F}=\mathrm{U} \times \frac{\mathrm{n}-2}{\mathrm{Q}}
$$

...where $U=\sum_{\mathrm{i}=1}^{\mathrm{n}}(\hat{\mathrm{y} i}-\overline{\mathrm{y}})^{2}$ is the sum of error square, $Q=\sum_{i=1}^{n}\left(y_{i}-\hat{y} i\right)^{2}$ is regression sum of squares, $y_{i}$ is the annual mean aridity value in the ith year (and $\hat{y} i$ is its regression value), amd $\bar{y}$ is the average value of aridity in 50 years $(\mathrm{n}=50$ for this paper). According to the significant test results, the change trend is divided into four categories: significantly decreased $\left(\theta_{\text {slope }}<0, P<0.05\right)$, not significantly decreased $\left(\theta_{\text {slope }}<0\right.$, $P>0.05)$, significantly increased $\left(\theta_{\text {slope }}>0, P<0.05\right)$, and not significantly increased $\left(\theta_{\text {slope }}>0, P>0.05\right)$.

\section{Moving Average Method}

Moving average is equivalent to lowpass filtering and the arithmetic mean of all outliers is made to determine the trend of the change, and the period in which the sequence is shorter than the sliding length is greatly weakened. For a sequence $\mathrm{x}$ whose sample is $\mathrm{n}$, the moving average sequence is expressed as Formula 4:

$$
\widehat{x_{j}}=\frac{1}{n} \sum_{j=1}^{k} x_{i+j+1} \quad(j=1,2, \ldots, n-k+1)
$$

$\ldots$ where $\mathrm{k}$ is the moving step length, which is 10 in this paper.

\section{Mutation Analysis}

Mann-Kendall statistical test (MK) is a nondistribution test, and is also known as a non-parametric statistical test [10] in which the data doesn't need to be in a particular order and is not affected by outliers. It was 
recommended by the World Meteorological Organization (WTO) and applied to the analysis of time series change and to detect the abrupt point in series. The principle of this method is: Assuming an original time series data for $\mathrm{x}_{1}, \mathrm{x}_{2}, \ldots, \mathrm{x}_{\mathrm{n}}, \mathrm{m}_{\mathrm{i}}$ represents the cumulative of ith sample in which $x_{i}$ is greater than $x_{j}(1 \leq j \leq i)$, then the statistic is defined as:

$$
\mathrm{d}_{\mathrm{k}}=\sum_{\mathrm{i}=1}^{\mathrm{k}} \mathrm{m}_{\mathrm{i}} \quad(2 \leq \mathrm{k} \leq \mathrm{n})
$$

In the original sequence of random independent construction, the mean value and the variance of $d_{k}$ were $\mathrm{E}\left(\mathrm{d}_{\mathrm{k}}\right)$ and $\operatorname{var}\left(\mathrm{d}_{\mathrm{k}}\right)$ :

$$
\begin{gathered}
\mathrm{E}\left(\mathrm{d}_{\mathrm{k}}\right)=\mathrm{k}(\mathrm{k}-1) / 4 \operatorname{var}\left(\mathrm{d}_{\mathrm{k}}\right)= \\
=\mathrm{k}(\mathrm{k}-1)(2 \mathrm{k}+5) / 72
\end{gathered}
$$

Standardized the above formula to obtain formula 7 :

$$
\mathrm{UF}_{\mathrm{k}}=\frac{\mathrm{d}_{\mathrm{k}}-\mathrm{E}\left(\mathrm{d}_{\mathrm{k}}\right)}{\sqrt{\operatorname{var}\left(\mathrm{d}_{\mathrm{k}}\right)}}
$$

$\mathrm{UF}_{\mathrm{k}}$ consists of a UF curve and the reverse curve $\mathrm{UB}$, which intersect at a certain point. If the intersection is through the 0.05 significance level, it can be conclude that the intersection is the mutation point in the given date series.

\section{Wavelet Transformation Analysis}

Wavelet transformation works as a mathematical microscope, and it is a kind of time-frequency domain analysis method, between square wave analysis (pure time domain) and traditional Fourier transformation (pure frequency domain) [11]. It is a kind of signal time-scale analysis method developed in the early 1980s to study the evolution of different time scales, and has multi-resolution characteristics. At present, the wavelet transform analysis can be used to discriminate the periodic change of climate factors contained in the sequence of climatological data at different time scales. In this paper, the standard Morlet wavelet was used to research the periodic change of aridity, because it has a very good sensitivity and time frequency analysis function [12]. The specific calculation algorithm is as follows:

For wavelet function $\varphi(t)$ that satisfies some conditions, wavelet transformation of time series is:

$$
W_{f}(a, b) \int_{-\infty}^{+\infty} f(t) \varphi_{a b}^{*}(t) d t=\frac{1}{\sqrt{2}} f(t) \varphi^{*}\left(\frac{t-b}{a}\right) d t
$$

$\ldots$ in which $W_{f}(a, b)$ is wavelet transformation or wavelet transformation coefficient; $\varphi_{\mathrm{ab}}(t)$ is complex conjugate function; a is scale factor that shows cycle length of wavelet; and $b$ is time factor, which shows translation of time. From wavelet analysis, frequency characteristics and time-frequency characteristics of time series at any time could be obtained. The wavelet chosen in this study is a standard Morlet wavelet $\varphi(t)$, which has great sensitivity and time frequency analysis functions.

$$
\varphi(t)=\left(1-t^{2}\right) \exp \left(-t^{2} / 2\right)
$$

\section{Results and Discussion}

\section{Spatial Distribution of Aridity in Inner Mongolia}

We used ArcGIS spatial analysis tools to obtain the spatial distribution of aridity in each decade in Inner Mongolia. It can be seen from Fig. 2 that the aridity of Inner Mongolia gradually increased from west to northeast. According to the classification of drying degree, the western part of Inner Mongolia was in a state of severe dryness, the central region was in a state of medium dryness, and the eastern region was in a state of wetness; an aridity index of less than 10 appeared in Alxa, which belongs to the western desert area of Inner Mongolia, while Hunlunbuir's aridity index is more than 40; and the area of each aridity degree is different in each decade.

According to the area percentage of different aridity degrees at variation periods (Table 1), the moderate dryness was listed in the first place, followed by above 30 degree aridity level, and the smallest was severe

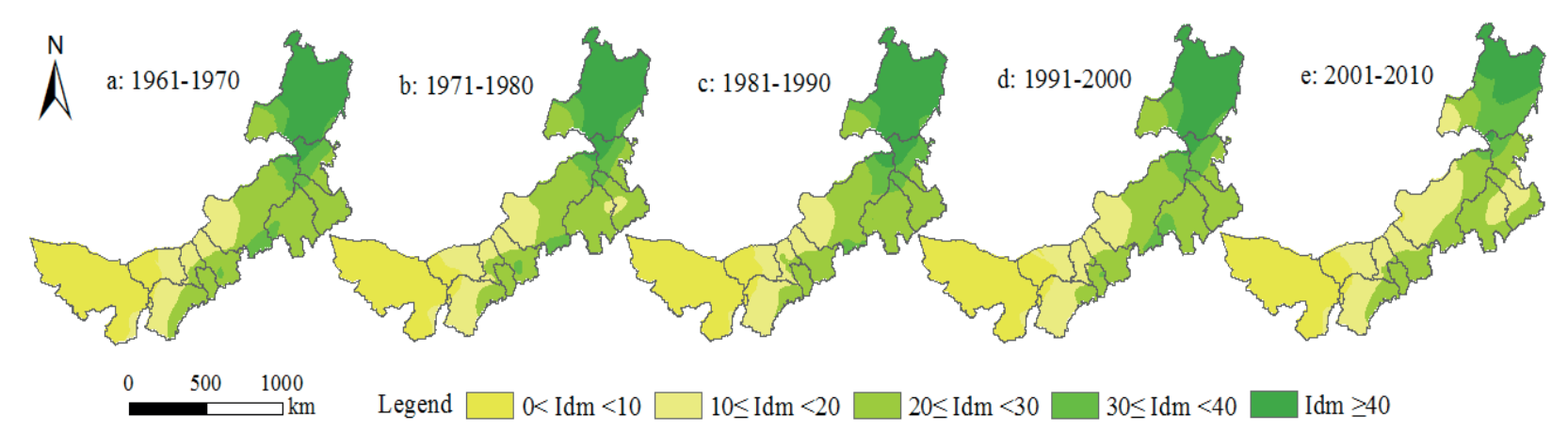

Fig. 2. Spatial distributions of aridity index in each decade. 
Table 1. Area statistical results of average aridity index classification in each decade in Inner Mongolia (\%).

\begin{tabular}{|c|c|c|c|}
\hline $\begin{array}{c}\text { Categories } \\
\text { Year }\end{array}$ & $\begin{array}{c}\text { Severe } \\
\text { dryness }\end{array}$ & $\begin{array}{c}\text { Moderate } \\
\text { dryness }\end{array}$ & Wetness \\
\cline { 2 - 4 } & $0<\mathrm{I}_{\mathrm{dm}}<10$ & $10 \leq \mathrm{I}_{\mathrm{dm}}<30$ & $\mathrm{I}_{\mathrm{dm}} \geq 30$ \\
\hline $1961-70$ & 24.15 & 48.15 & 27.70 \\
\hline $1971-80$ & 23.61 & 49.81 & 26.58 \\
\hline $1981-90$ & 25.50 & 45.86 & 28.64 \\
\hline $1991-2000$ & 24.88 & 48.71 & 26.41 \\
\hline $2000-10$ & 24.15 & 56.27 & 19.58 \\
\hline
\end{tabular}

dryness. The area of three aridity degrees was the same in the $1960 \mathrm{~s}, 1970 \mathrm{~s}, 1980 \mathrm{~s}$, and $1990 \mathrm{~s}$. In the $21^{\text {st }}$ century, moderate aridity took up $56.27 \%$ of the total area of the study subject aridity and it was larger than the other four years' area, and aridity degree which is above 30 dropped to $19.58 \%$. In conclusion, the climate of Inner Mongolia has been getting arid since the $21^{\text {st }}$ century.

\section{Temporal Change Characteristics of Aridity in Inner Mongolia}

The following could be concluded from Fig. 3: the fluctuations of aridity were reduced as time went by, the changes were obvious in the early 21 st century because precipitation was decreasing while the temperature was rising [13-14], and the maximum aridity value appeared in 1969 and the minimum appeared in 2007.

The Mann-Kendall method was adopted for the average aridity sequence mutation test. The average annual aridity degree of Inner Mongolia in the last 50 years began a downward trend in the early $1990 \mathrm{~s}$. The aridity has been rising since 2003. On the MK statistics, the UF curve appeared as a downward trend and the line was larger than 0.05 significant levels. UF and UB intersected in 199495 , and it could be seen that it was an obvious mutation phenomenon. To summarize, the average aridity of Inner Mongolia started from 1995.
Morlet wavelet analysis was used to periodically analyze annual aridity in this study. The variation tendency of wavelet coefficient and fluctuation of climate signal were basically identical. The center of the contour is the center of dry-wet, and positive wavelet is humid and negative wavelet is arid. The $\mathrm{x}$ axis that the central value corresponds with is the year and the $\mathrm{y}$ axis is variation period of sequence. The results of wavelet transformation analysis of aridity in Inner Mongolia during the past 50 years are shown in Fig. 4. The wavelet variance diagram can reflect the signal fluctuation with the scale and can be used to determine the relative strength of different scale disturbances and the primary period in the signal.

It can be seen from Fig. 4 that the aridity of Inner Mongolia contained a number of different periodic and oscillation centers, followed by obvious decadal and annual changes. There are 49a, 25a, and 7a oscillation centers in annual mean aridity in Inner Mongolia; the oscillation period of 49 a continued from the 1960s to 2010 , with three alternate cycles of dry-wet, including two dry and one wet period. The oscillation cycle of $25 \mathrm{a}$ was very obvious and also continued from the 1960s to the $21^{\text {st }}$ century, covering two dry and one wet period and appeared as a replacement in about 15 years. For the $7 \mathrm{a}$ period, it didn't have an obvious oscillation period. For the time scale of 50 years, Inner Mongolia is still in the dry period and the contour of the oscillation period has not been closed; therefore, it can be speculated that Inner Mongolia still continues for a period of dryness after 2010.

\section{Spatial Variations of Aridity in Inner Mongolia}

Using the trend analysis method, the study analyzed the change of annual average aridity of Inner Mongolia in terms of spatial characteristics. As shown in Fig. 5, the aridity change of Inner Mongolia was significantly different in terms of spatial distribution in the past 50 years. In a given 0.05 significance level, the average annual aridity of the Inner Mongolia region had a tendency to reduce by $82.6 \%$ and $24.7 \%$ of the area, particularly eastern Hulunbuir of Inner Mongolia, western Hinggan
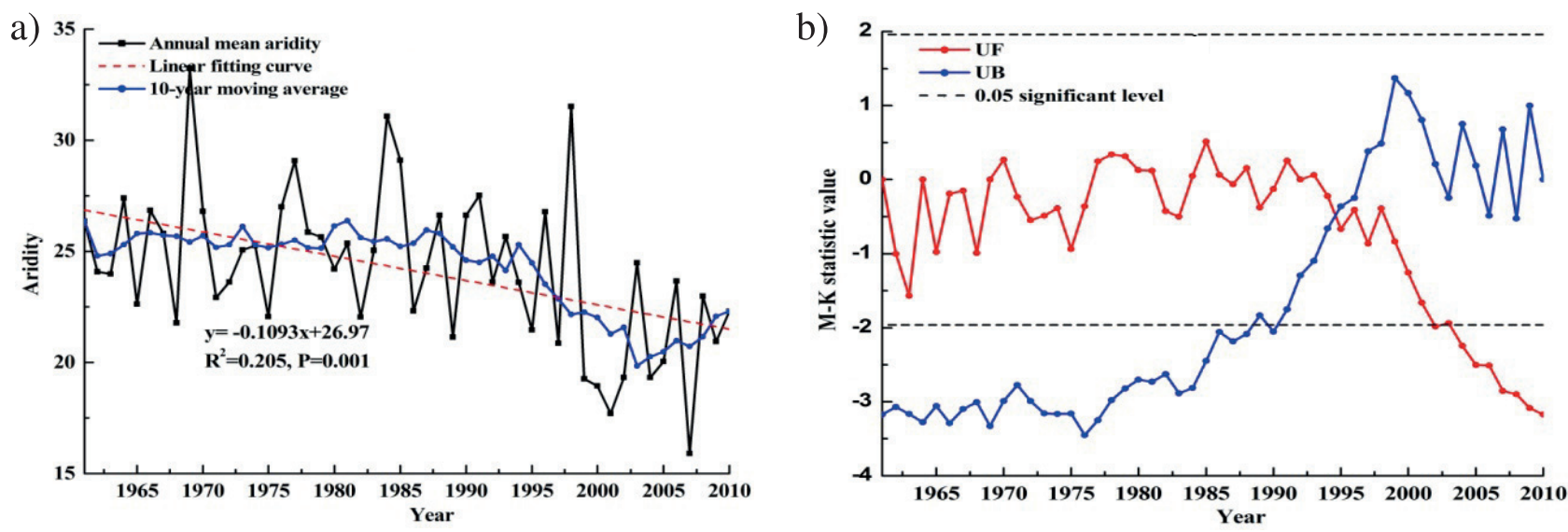

Fig. 3. Annual change trend a) and mutation test b) of annual mean aridity index in Inner Mongolia, 1961-2010. 


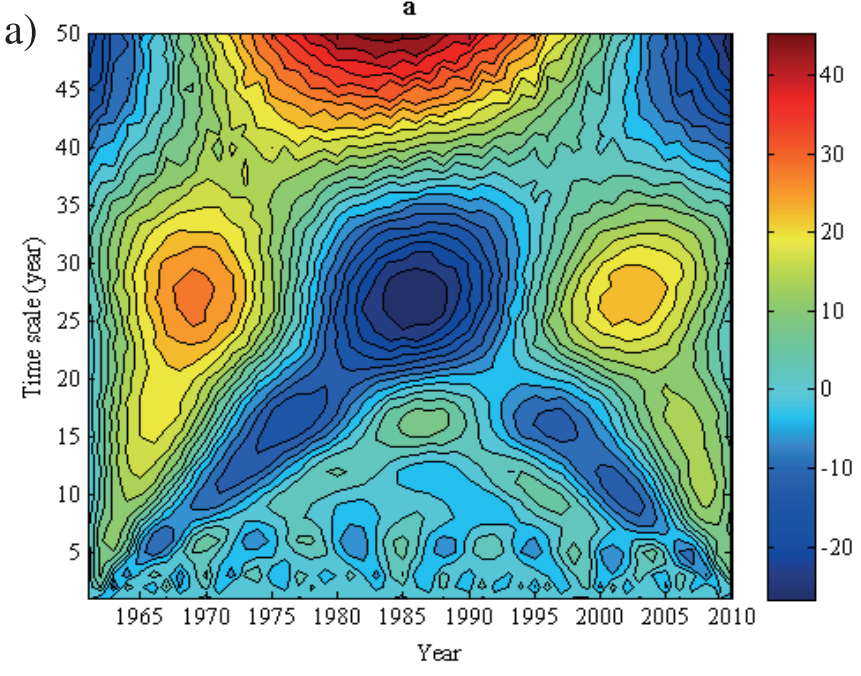

b)

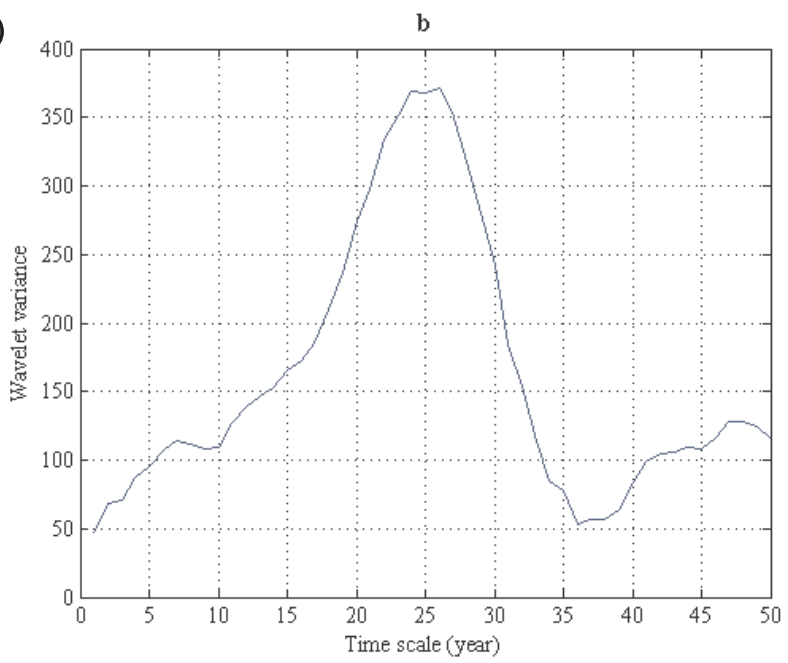

Fig. 4. Wavelet transformation a) and wavelet variance b) of annual mean aridity index in Inner Mongolia, 1996-2010.

League of Inner Mongolia, and southeast Xilingol of Inner Mongolia because the temperature was significantly increasing and precipitation was decreasing. $17.4 \%$ of the average annual aridity degree has increased and one of the examples was the Alxa; $2.5 \%$ of the aridity degree significantly increased, representing the humidity degree increased in this region.

\section{Spatial Shifts of Different Grades of Aridity in Inner Mongolia}

From the spatial distribution of any of the above aridity degree analysis, the different levels of aridity of
Inner Mongolia have moved to the north or to the east. In order to analyze the spatial displacement condition of aridity degree range, the study selected five aridity degree classification interval values $(\mathrm{Idm}=10,20,30,40$, 50). Fig. 6 shows each of the selected aridity contours, and their changes of location were computed to analyze the spatial displacement in each decade. $\mathrm{X}$ is longitude and positive $\mathrm{x}$ means eastward-moving, while negative $\mathrm{x}$ means westward-moving; $\mathrm{Y}$ is latitude and positive $\mathrm{y}$ means northward-moving, otherwise it means moving to the south.

When aridity degree of different time periods with spatial displacement was combined, the position of aridity

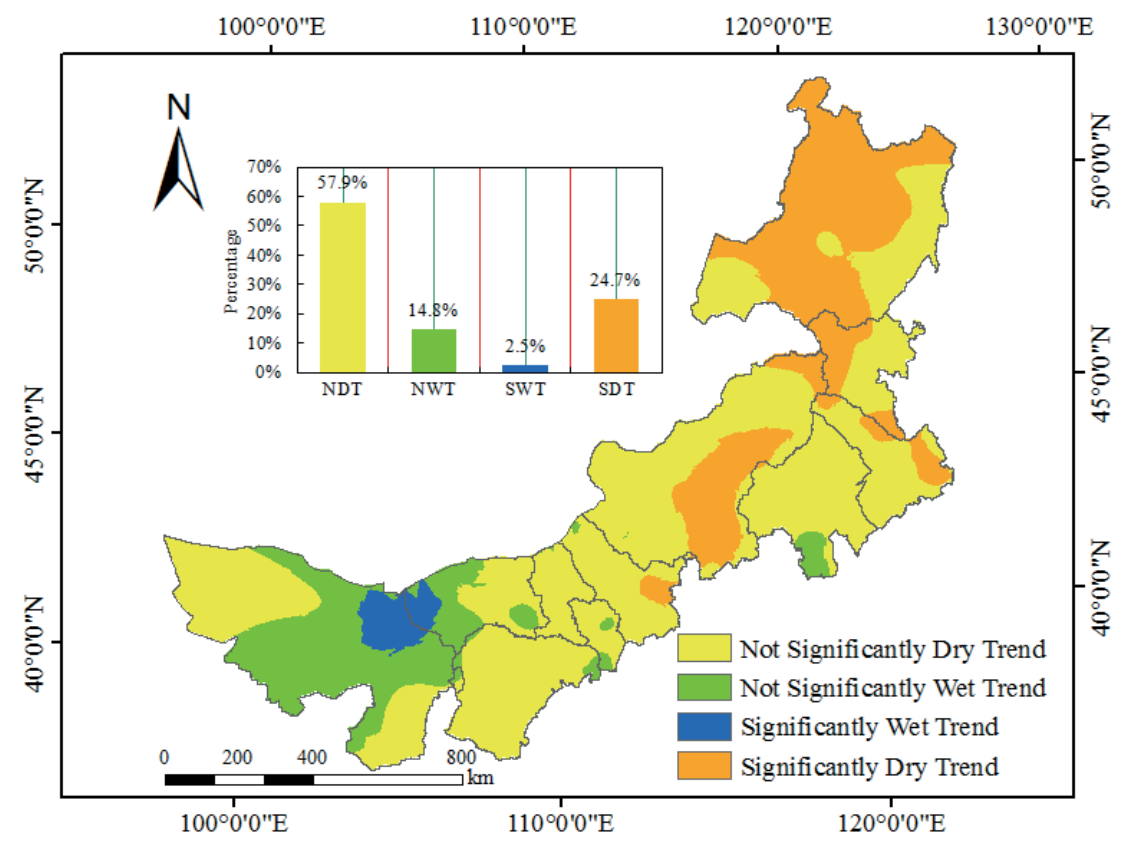

Fig. 5. Spatial distribution of change trend rate of average annual aridity index in Inner Mongolia during 1961-2010 at the 0.05 significance level. 


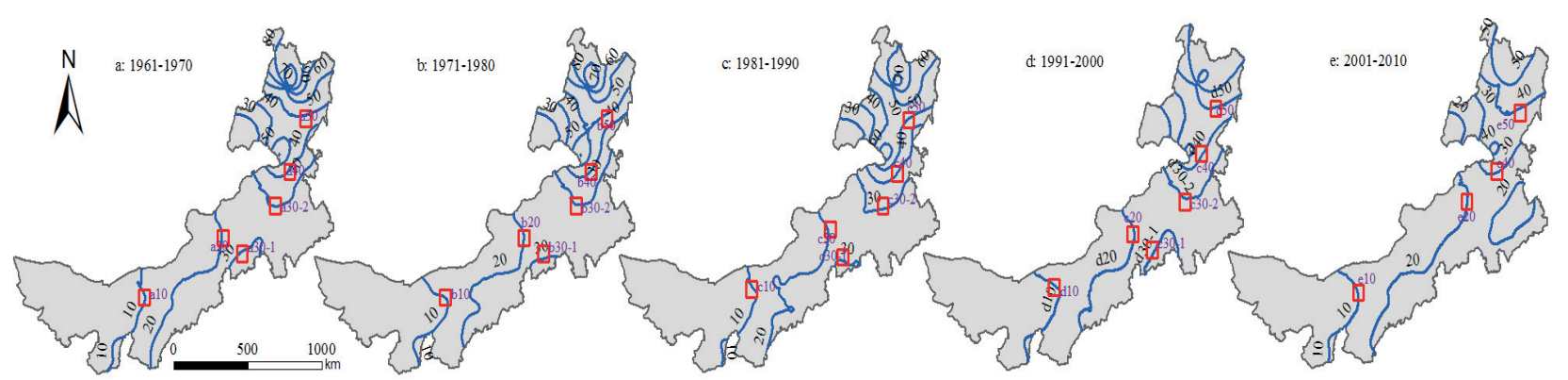

Fig. 6. Contours of aridity index in each decade. The red box represents the contours that need to do spatial displacement.

degree range changed, especially at the beginning of the 21 st century. Compared to the 1960 s and 1970s, 20, 302 , and 40-3 aridity contour positions moved toward the northeast and 10,30-1, and 50 aridity contours moved southwest. Compared to the 1970s and 1980s, the contour of different aridity degrees moved southward and it was the main trend. In the $1990 \mathrm{~s}$, it is obvious that the contour of aridity degree for 10 and 20 moved in the longitude direction and other contour of aridity degree moved along with the latitude. In the 1990 s and early 21 st century, it is clear that the contour of aridity degree moved toward longitude. In the 21 st century, 30-1 contour of aridity degree became 20 contour, and it could be seen from Tongliao and central Chifeng, and it showed the climate aridity tendency. Compared with the 1960s, the contour of aridity degree position had changed a lot, and the range movement was larger than before along with latitude and longitude. The contour of aridity degree of 10 was the main trend and this led to an increase in the severe aridity area. Moderate aridity of 20 and 30 degrees has been moving northwest and this contributed to the increase in the area of semi-aridity. Moreover, the contour of aridity degree of
30, which represents humidity degree moving in the north latitude direction, caused a decline in the humid areas. This result was the same as the area of aridity degree level.

\section{Discussion}

The previous studies of grassland climate variation focused mainly on single-factor analysis about temperature and precipitation. The climate changes of different regions demonstrated different characteristics [15-16]. The results of climate changes differ from high temperature/ humid, low/high humidity, and high temperature and low humidity. That is to say, temperature and precipitation which are at different developmental steps led to the difference in climate aridity itself. The research used aridity index of regularity about spatial variation analysis and took precipitation and temperature into consideration in order to reflect a specific region's response to global warming. It has great necessity to do related studies in Inner Mongolia, because it can offer a scientific basis for grassland desertification and grassland degradation.

Table 2. The location change of $\mathrm{I}_{\mathrm{dm}}$ grade range in different periods (positive $\mathrm{x}$ means eastward-moving while negative $\mathrm{x}$ means westwardmoving; positive y means northward-moving, otherwise moving to the south).

\begin{tabular}{|c|c|c|c|c|c|c|}
\hline $\mathrm{I}_{\mathrm{dm}}$ & $\mathrm{x} / \mathrm{y}$ & $1960 \mathrm{~s}-70 \mathrm{~s}$ & $1970 \mathrm{~s}-80 \mathrm{~s}$ & $1980 \mathrm{~s}-90 \mathrm{~s}$ & $1990 \mathrm{~s}-2000 \mathrm{~s}$ & $1960 \mathrm{~s}-2000 \mathrm{~s}$ \\
\hline 10 & $\mathrm{x} /(\mathrm{km})$ & -18.3 & 44.2 & -22.7 & -18.6 & -15.40 \\
\hline & $\mathrm{y} /(\mathrm{km})$ & -28.1 & 13.1 & 5.3 & -3.7 & -13.36 \\
\hline 20 & $\mathrm{x} /(\mathrm{km})$ & 29.8 & -12.9 & 51.4 & 75.8 & 144.16 \\
\hline & $\mathrm{y} /(\mathrm{km})$ & 34.1 & -17.7 & 37.7 & 63.8 & 117.89 \\
\hline $30-1$ & $\mathrm{x} /(\mathrm{km})$ & -42.7 & 2.6 & 64.7 & -- & -- \\
\hline & $\mathrm{y} /(\mathrm{km})$ & -49.3 & -29.9 & 72.7 & -- & -- \\
\hline $30-2$ & $\mathrm{x} /(\mathrm{km})$ & 11.9 & -68.2 & 67.3 & 17.5 & 28.51 \\
\hline & $\mathrm{y} /(\mathrm{km})$ & 13.0 & -77.3 & 79.2 & 87.0 & 101.98 \\
\hline 40 & $\mathrm{x} /(\mathrm{km})$ & 18.6 & -33.6 & 19.0 & 0.1 & 4.17 \\
\hline & $\mathrm{y} /(\mathrm{km})$ & 36.0 & -66.4 & 55.2 & 251.3 & 276.12 \\
\hline 50 & $\mathrm{x} /(\mathrm{km})$ & -4.6 & 17.6 & -1.9 & -25.2 & -14.21 \\
\hline
\end{tabular}


Grassland degradation is noted as a significant ecological problem that is threatening ecological safety and grazing sustainable development. Therefore, grassland ecological safety is given great importance by ecologists and the government. Our research investigated the current situation of grassland degradation and analyzed the situation and determined possible solutions to the problems. Though it gained a great number of research achievements, the arguments still exist as for whether the grassland degradation originated from grazing or climate aridity tendency.

The grassland of Inner Mongolia is seen as an important part of our country's grassland. Because of the arid and semi-arid climate characteristics, evaporation is higher than precipitation and low/high temperature has a significant effect on evaporation. Therefore, by considering the precipitation and temperature data, the analytical meaning of climate change is strengthened through working out aridity degree and humidity degree. The results can explain regional differences and trend differences in arid tendency of grassland climate. The research begins with regularity of aridity degree of climate at different periods and different regions and aims to provide a scientific basis and some practical suggestions on grassland desertification and grassland degradation.

\section{Conclusions}

Our study used such research methodology as the de Martonne model and ArcGIS in order to explore the regularity of spatio-temporal variations of aridity in Inner Mongolia over the past 50 years. The conclusions are as follows:

1. During 1961 to 2010 , the aridity degree of Inner Mongolia was decreasing and was mainly characterized by moderate aridity; the decreasing area of aridity took up $82.6 \%$ while the increasing aridity degree area only occupied $17.4 \%$.

2. The mutation point of aridity appeared in 1995, and the dryness significantly increased after this year; there are $49 \mathrm{a}, 25 \mathrm{a}$, and $7 \mathrm{a}$ primary periods in annual mean aridity and Inner Mongolia was still at the stage of dryness, which might last for a long time.

3. With the spatial shifts of different degrees of aridity from 1960 to 2010, contours less than 30 shifted toward longitude direction and contours greater than 30 moved toward latitude direction. This phenomenon will lead to an increase in the drought area in Inner Mongolia.

\section{Acknowledgements}

This study was financially supported by the National Key Technology R\&D Program of China under Grant (No.2013BAK05B01 and No.2013BAK05B02).

\section{References}

1. PARRY M.L., CANZIANI O.F., PALUTIKOF J.P., LINDEN P.J.V.D., HANSON C.E. Climate change 2007: impacts, adaptation and vulnerability. contribution of working group ii to the fourth assessment report of the intergovernmental panel on climate change. summary for policymakers. Astronomische Nachrichten. 332 (7), 697, 2011.

2. CLARK W.C., JAGER J. Climate change 1995: the science of climate change. Environment Science \& Policy for Sustainable Development. 39 (9), 23, 1997.

3. YANG J.P., DING Y.J., CHEN R.S., LIU L.Y. The interdecadal fluctuation of dry and wet climate boundaries in China in recent 50 years. Acta Geographica Sinica. 57 (6), 655,2002

4. LIU B., MA Z.G. Area change of dry and wet regions in China in the past 45 years. Arid Land Geography. 30 (1), 7, 2007.

5. ZHENG G.F., CHENG X.G., ZHAO G.P., NA L., SUN Y.C. Evolvement law of surface humid status and extreme drywet events in Ningxia. Journal of Desert Research. 27 (2), 326, 2007.

6. PU Z.C., ZHANG S.Q., WANG S.L., ZHOU X.L., FENG Z.M. The spatial-temporal variation characteristic of dry-wet climate in recent 48 years in Xinjiang province. Journal of Desert Research. 31 (6), 1563, 2011.

7. WANG H.M., LI Z.H., HAN G.D., ZHANG Y., WU L., SONG G.B. The analysis on the spatial-temporal change of climate aridity in Xilinguole steppe. Acta Ecologica Sinica. 30 (23), 6538, 2011.

8. RORA V. K. The use of the aridity index to assess climate change effect on annual runoff. Journal of Hydrology. 265, 164, 2002.

9. MAO F., SUN H., YANG H.L. Research progress in dry/ wet climate zoning. Progress in Geography. 30 (1), 17, 2011

10. CHUN X., DAN D., BI L., LIU M.P., LIU Y., HU H. Climate change in Alxa plateau over recent 60 years. Journal of China Hydrology. 33 (2), 43, 2013.

11. LI M., XIA J., CHEN S.M., MENG D.J. Wavelet analysis on annual precipitation around 300 years in Beijing area. Journal of natural resources. 26 (6), 1001, 2011.

12. JIANG X.Y., LIU S.H., MA M.M., ZHANG J., SONG J. A wavelet analysis of the precipitation time series in Northeast China during the last 100 years. Geographical Research. $\mathbf{2 8}$ (2), 354, 2009.

13. BAO Y., LI X.B., LI C., HUANG L.M., YU J. Spatialtemporal distribution characteristics of temperature in Inner Mongolia during 1961-2007. Journal of Arid Land Resources and Environment. 24 (12), 80, 2010.

14. BAO Y., LI X.B., HUANG L.M., ZHANG Y.X., WANG H. Spatial-temporal distribution characteristics of precipitation in Inner Mongolia from 1961-2007. Arid Land Geography. 34 (1), 52, 2011.

15. DU J., BIAN D., HU J., LA B., ZHOU K.S. Responses of climatic change on surface humid index in Northern Tibet during the period of 1961-2006. Acta Ecologica Sinica. 29 (5), 2437, 2009

16. SHANG Z.B., GAO Q. Assessing the sensitivity of China water condition to global climate changes. Acta Ecologica Sinica. 21 (4), 528, 2001 